\title{
Demanda e oferta no encontro entre profissionais de saúde mental e familiares de pessoas com sofrimento psíquico
}

\author{
Supply and demand in the meetings between mental health \\ professionals and family members of people with mental disorders
}

Teresinha Cid Constantinidis ${ }^{1}$

Angela Nobre de Andrade ${ }^{2}$

${ }^{1}$ Departamento de Educação Integrada em Saúde, Centro de Ciências da Saúde, Universidade Federal do Espírito Santo (UFES). R. Marechal Campos 1468, Maruípe. 29040-090 Vitória ES

Brasil.teracidc@uol.com.br ${ }^{2}$ Programa de PósGraduação em Psicologia UFES.
Abstract This paper is a development of a doctoral thesis presented at the Federal University of Espirito Santo. It seeks to analyze the elucidation of needs, development of supply and demand in the provision of care and the relationship between mental health professionals and family members of people with mental disorders. A qualitative research approach was used as the method of choice to achieve the proposed objectives. Semi-structured interviews were conducted with mental health professionals from two psychosocial care centers (CAPS) in the city of Vitoria, Espirito Santo, and with family members of frequenters of these institutions. After thematic analysis of content, senses, meanings and values assigned to the needs, supplies and demands present in this relationship were revealed. It highlighted the disparity between supply and demand and the lack of awareness of the needs of family members and their demands related to the routines of mental institutions. Using ethics in the philosophy of Spinoza as a benchmark, the ramifications of this process are discussed in the meetings between mental health professionals and family members of people with mental disorders and the micropolitics of the provision of care in the context of these actors.

Key words Needs and demands of health services, Relations between health professionals and family members, Mental health services
Resumo Este artigo é um desdobramento de tese de doutorado defendida pela Universidade Federal do Espírito Santo. Pretende-se analisar a elucidação de necessidades, a elaboração de demanda e oferta, no processo de produção de cuidado, na relação entre profissionais de saúde mental e familiares de pessoas com sofrimento psíquico. A perspectiva qualitativa de investigação configurou-se como método para alcançar os objetivos propostos. Foram realizadas entrevistas semiestruturadas com profissionais de saúde mental de dois centros de atenção psicossocial (CAPS) do município de Vitória ES e com familiares de usuários destas instituições. Após análise temática do conteúdo, foram evidenciados sentidos, significados e valores atribuídos às necessidades, demandas e ofertas, presentes nessa relação. É evidenciada a disparidade entre demanda e oferta, a desvalorização, $o$ desconhecimento das necessidades dos familiares $e$ as demandas dos familiares relacionadas à lógica manicomial. Tendo como referência a ética na filosofia de Espinosa, são discutidas as consequências do encontro entre profissionais de saúde mental e familiares de pessoas com sofrimento psíquico e a micropolítica da produção de cuidado no contexto desses atores.

Palavras-chave Necessidades e demandas de serviços de saúde, Relações profissional-família, Serviços de saúde mental 


\section{Introdução}

Com a consolidação do processo de desinstitucionalização, entre as tarefas dos serviços de assistência em saúde mental está a afirmação da cidadania da pessoa com sofrimento psíquico, promovendo ou o seu retorno ou sua permanência em seu território, garantindo sua livre circulação pelos serviços, comunidade e cidade. A construção de uma rede comunitária de cuidados, capaz de acolher a pessoa em sofrimento mental é crucial para a consolidação destas propostas e garantir serviços substitutivos ao hospital psiquiátrico. O território é o organizador da rede de atenção à saúde mental, orientando as ações de todos os seus equipamentos, construindo coletivamente as soluções e os cuidados nesta área ${ }^{1}$.

Nesse sentido, os Centros de Atenção Psicossocial (CAPS), os Serviços Residenciais Terapêuticos, o Auxílio de Reabilitação Psicossocial "De volta pra casa", expandiram a possibilidade da pessoa com sofrimento psíquico estar junto à família e à comunidade. De maneira geral, estes serviços vão ao encontro da proposta de utilização intensiva de um conjunto amplo e complexo de tecnologias terapêuticas e práticas psicossociais dirigidas a manter a pessoa com transtorno mental fora da internação.

A família, que antes era apenas a chave determinística da doença mental, passa a ser o lugar primeiro de intervenção de reabilitação, a ter atenção maior dos serviços de saúde, a ser assistida e incluída nos projetos ampliados de atenção em saúde mental. No desenvolvimento dos projetos terapêuticos está previsto o preparo para o retorno à residência e à inserção domiciliar da pessoa anteriormente internada, assim como abordagem dirigida à família, de acordo com a Portaria no 251/GM do Ministério da Saúde, de 31 de janeiro de $2002^{2}$.

O CAPS é um dispositivo estratégico dessas ações, por ser um serviço de saúde aberto, comunitário, que oferece atendimento diário às pessoas com transtornos mentais severos e persistentes, realizando o acompanhamento clínico e a reinserção social dessas pessoas. Por meio de ações intersetoriais, além de facilitar o acesso ao trabalho, lazer, exercício dos direitos civis, o CAPS visa fortalecer os laços familiares e comunitários das pessoas com transtornos mentais. Tem ainda como objetivo, evitar internações e/ ou reinternações em hospitais psiquiátricos, regular a porta de entrada da rede de assistência na sua área de atuação e dar suporte à atenção à saúde mental na rede básica². Para garantir os cuidados à pessoa com transtorno mental, que garanta uma rede de apoio em seu território, as ações voltadas aos familiares devem ocupar lugar de destaque.

A assistência e suporte psicossocial aos familiares têm importância fundamental, pois no cotidiano partilhado com a pessoa com transtorno mental, as famílias enfrentam problemas, dificuldades ou eventos adversos que podem afetá-las significativamente. São os familiares que geralmente identificam algum problema, buscam auxílio dos serviços, tornam-se responsáveis pela administração das prescrições médicas e devem enfrentar e manejar os momentos de crise, de agravamento do quadro sintomatológico. São várias as dificuldades cotidianas que geram encargos e, por isso, têm que redimensionar as expectativas quanto ao futuro de seu familiar com sofrimento psíquico e quanto ao próprio futuro. Esses encargos afetam a vida afetiva, social e econômica das famílias, que também entram em sofrimento. Assim, entende-se que, além de aliados no processo de tratamento, os familiares também necessitam de cuidados.

Diante disso, os profissionais e os planejadores de saúde concordam sobre a importância e a necessidade de prover desses serviços à família, mas vários fatores ainda contribuem para dificultar sua implantação e condução efetivas. Faz parte da experiência de profissionais de saúde mental oferecer atendimentos para os familiares e eles não "aderirem", comparecendo de forma muito irregular ou nunca comparecendo, conforme citado em trabalhos de Colvero et $\mathrm{al}^{3}{ }^{3}$ e Rosa ${ }^{4}$.

São vários os fatores que podem contribuir para a não efetivação desses atendimentos. Estudos apontam que muitas vezes as técnicas terapêuticas sobrepujam a família, sua singularidade, sua história, suas particularidades na relação com seu familiar com transtorno mental, como apontam estudos de Villares e Mari ${ }^{5}$ e Rosa ${ }^{6}$. Além disso, tem-se observado que cada serviço ou equipe se organiza de maneira própria para abordar a família e nem sempre com o devido conhecimento das suas reais necessidades e condições materiais, psicossociais, de saúde e de qualidade de vida. Gonçalves e Sena ${ }^{7}$ apontam que as propostas advindas da Reforma Psiquiátrica Brasileira têm evidenciado a fragilidade do sistema de saúde para oferecer outro tipo de atendimento que não aquele centrado no leito hospitalar.

Tais fragilidades parecem advir da dinâmica da relação que se estabelece entre as políticas públicas de saúde mental, dos serviços de saúde mental, dos profissionais atuantes na 
área e familiares dos usuários que, em seu cruzamento, geram como efeito o desencontro. Tomamos como ponto de partida para este estudo o encontro entre esses profissionais e esses familiares. Encontro entendido, segundo a ótica espinosana ${ }^{8}$ como a capacidade de afetarmos e de sermos afetados por outros seres. O bom encontro se dá quando há aumento de potência de agir de cada um dos atores da relação, podendo haver união de forças, aumentando as possibilidades de ação desses sujeitos. No Tratado Político', Espinosa afirma que se duas pessoas concordam entre si e unem suas forças, terão maior poder conjuntamente e, consequentemente, um direito sobre a Natureza que cada uma delas não possui sozinha.

Envolvidas também nessa relação, de forma mais ampla, estão as propostas da política de saúde mental, que compõe o contexto em que se dá esse encontro.

Nessa proposta de conhecer essa relação, é importante pesquisar quais as ideias e afetos que permeiam a interação entre profissionais e familiares. $\mathrm{O}$ afeto, segundo Espinosa, é determinado pelas ideias e o essencial é ver quais são aquelas que determinam os afetos envolvidos nessa relação.

À primeira vista, a demanda é o ponto chave do encontro entre profissionais de saúde mental e familiares de pessoas com sofrimento psíquico. A demanda deveria, a princípio, partir de uma necessidade e seria a atitude do usuário em buscar e acessar serviços de saúde e se beneficiar com o atendimento recebido, conforme aponta Pinheiro ${ }^{10}$. Os atendimentos oferecidos por esses profissionais fariam, portanto, parte da oferta para responder às demandas dos usuários, e o afeto resultante desse encontro, na leitura espinosana, seria a alegria, aumentando a potencia de ação entre as pessoas, como acontece nos bons encontros. Porém, segundo Pinheiro ${ }^{10}$, oferta e demanda são construídas de maneira dinâmica, que inclui a objetividade e/ou subjetividade de seus atores, assim como suas falas e práticas no interior das instituições.

Neste sentido, este estudo pretende analisar o processo de elucidação das necessidades, da demanda e oferta de atendimentos, no processo de produção de cuidado, na relação entre profissionais e familiares de usuários de serviços de saúde mental.

\section{Percurso metodológico}

A perspectiva qualitativa de investigação mostrou-se o método mais fecundo para alcançar os objetivos da pesquisa. Seguindo esta proposta ${ }^{11,12}$, trabalhar com o universo dos significados, dos motivos, das aspirações, das crenças, dos valores, das atitudes - além de se ocupar com o nível da realidade não visível, que precisa ser exposta e interpretada -, são características da pesquisa qualitativa.

O projeto da pesquisa que deu origem a este estudo, por se tratar de pesquisa que envolve seres humanos - seguindo a Resolução 196/96 ${ }^{13}$ do Conselho Nacional de Saúde -, foi aprovado pelo Comitê de Ética em Pesquisa do Centro de Ciências da Saúde da UFES. Participaram deste estudo, familiares de usuários e profissionais de saúde mental de dois CAPS da cidade de Vitória/ES. A escolha do CAPS como campo de estudo deu-se por ser um dos principais alicerces no cuidado no território e na possibilidade efetiva de trocas entre todos os sujeitos envolvidos na estrutura de um serviço constituinte de uma rede de cuidados, além de oferecer entre a ampla e diversa gama de ações, o atendimento familiar.

Como participantes da pesquisa, os familiares entrevistados tinham grau variado de parentesco com a pessoa com sofrimento psíquico (mãe, pai, irmã, esposa, marido, avó e avô), porém mantinham convivência cotidiana com ela. Foram entrevistados nove familiares. Chegou-se a este número pelo método de amostragem por saturação, isto é, depois de certo número de entrevistas, as informações passaram a se repetir e novas falas passaram a ter acréscimos pouco significativos em relação aos objetivos da pesquisa, inicialmente traçados.

Os profissionais entrevistados foram aqueles responsáveis por atendimento familiar nos CAPS, totalizando doze participantes, dentre eles: dois assistentes sociais, um médico, cinco psicólogos, um terapeuta ocupacional, um musicoterapeuta, um arteterapeuta e um enfermeiro. Esse número também foi fechado a partir de amostragem por saturação.

A técnica de coleta de dados foi a entrevista e a forma como foi conduzida, classifica-a, segundo Turato $^{14}$, no tipo semi-estruturada ou semidirigida de questões abertas. Os tópicos abordados com os familiares referiram-se, de forma geral, à visão e expectativas dessas pessoas em relação ao serviço de saúde mental e aos profissionais e aos atendimentos dispensados a eles. Com os profissionais, os tópicos abordados foram concernentes à dinâmica dos atendimentos familiares, sobre os diferentes dispositivos de atendimento aos familiares, sobre a relação que se estabelece nesses 
encontros. As entrevistas com os familiares, com duração média de 60 minutos, foram realizadas ou nos CAPS ou em seus domicílios. Com os profissionais, os encontros foram realizados exclusivamente nos CAPS e tiveram a mesma duração. $\mathrm{O}$ registro foi feito por intermédio de gravação magnética, com posterior transcrição de áudio.

O tratamento do material, a sua codificação, deu-se por intermédio da análise de conteúdo, segundo Bardin ${ }^{15}$. Há várias maneiras para analisar conteúdos de materiais de pesquisa. Esta pesquisa foi trabalhada na modalidade de análise temática. A análise temática, na descrição de Turato $^{14}$, procura nas expressões verbais temas recorrentes que fazem a sua aparição no interior de vários conteúdos mais concretos. Tendo em vista que este estudo não pressupõe uma análise quantitativa, as categorias foram sendo delineadas não necessariamente pela repetição de falas, mas também pela relevância dos relatos no encaminhamento das discussões.

\section{Resultados e discussão}

Conforme processo detalhado acima, os dados analisados apontaram regularidades discursivas que delinearam quatro categorias: (1) questionamento dos profissionais sobre a existência de demandas dos familiares, resultando na categoria intitulada: Que demanda? Quem demanda?; (2) Oferta e captura: oferta de atendimentos vivenciados pelos familiares como encargos; (3) Elucidação das necessidades X “a gente é que entende": a relação entre a forma de elucidação das necessidades dos familiares, realizadas pelos profissionais, e a oferta de atenção e cuidado; e (4) $\mathrm{O}$ que querem esses familiares?: Demandas dos familiares diante do cotidiano partilhado com o ente com transtorno mental grave.

\section{Que demanda? Quem demanda?}

Faz também parte da experiência desses profissionais de saúde mental, oferecer atendimentos para os familiares e eles não "aderirem", comparecendo de forma muito irregular, ou nunca comparecendo. Os relatos mostram que o investimento para manter esses atendimentos parte do profissional, numa oferta insistente. [...] Você vai, convida... tem toda uma equipe para atender essas pessoas e elas não vêm, precisa chamar, chamar, chamar... (Profissional 2).

Aqui vemos que o fluxo demanda-oferta não se aplica. A demanda que seria, a princípio, dos familiares é questionada pelos profissionais: [...] De quem é a demanda? Eu vejo muito a instituição demandando. Porque eu acho que a demanda tem que ser do familiar. Nem que a gente precise provocar isso, até instruir para que a demanda surja [...] (Profissional 2). Para esses profissionais, a lógica se inverte: são eles que demandam esse encontro com os familiares. Para eles, as faltas, o não comparecimento aos atendimentos indica que os familiares não têm essa demanda de atenção, necessitando haver o convencimento da importância daquilo que é oferecido. Mostram certo incômodo por serem os únicos a investir nesses dispositivos.

É importante ressaltar que existe mais de uma forma de analisar o processo de demanda -oferta na organização dos serviços. Uma delas é aquela que utiliza a dicotomia oferta-demanda, que imprime um caráter estático a essa relação e desconsidera os processos de subjetivação desses sujeitos. Nesta abordagem, a demanda está relacionada ou aos usuários ou aos consumidores, e a oferta ligada apenas aos profissionais e gestores dos serviços. Em relação a este tipo de análise, Pinheiro ${ }^{10}$ aponta que é uma forma de elaboração com estreita ligação com os conceitos econômicos clássicos que mantém distinção entre as categorias demanda e oferta, com consumidor ou usuário de um lado e prestador e seus agentes de outro lado, em uma ação descolada do contexto em que estão inseridos.

De outra forma, apesar de as práticas de saúde estarem referenciadas a uma organização colocada pela política de saúde, que valoriza o fluxo demanda-oferta, é importante considerar o processo de trabalho em saúde como um mundo rico com muitas possibilidades de atuação dos trabalhadores, o que traz a importância de considerar a micropolítica desse processo ${ }^{16}$.

Considerando os profissionais de saúde mental, existem aqueles que o campo de experiência, dentro da proposta de desinstitucionalização, é marcado por uma prática interdisciplinar que prioriza tecnologias mais relacionais para assistência aos usuários, valorizando o diálogo com a população. De forma diferente, existem aqueles que apenas colocam em prática as políticas e modelos propostos e muitos deles ou desconhecem ou se sentem despreparados em lidar com os familiares.

Os dados indicam que a idéia de cuidado dos referidos profissionais não coincide com a dos familiares. Apesar dos encargos de várias ordens enfrentados pelos familiares - que afetam a vida afetiva, social e econômica da família -, os dis- 
cursos desses atores evidenciam que eles não demandam o tipo de atendimento que está sendo oferecido pelos profissionais.

Franco e Merhy ${ }^{17}$ apontam que a ideia de cuidado, que se produz em um serviço de saúde, é resultado de um conjunto de representações que dão significado à assistência que se presta. Para os autores, se a ideia de cuidado, traduzida pelos atos assistenciais do serviço não estiver coincidindo com a dos usuários, pode-se tornar ruidoso os fluxos comunicantes na relação usuário-serviço de saúde e gerar conflitos e tensões que interditam a relação de cuidado. De acordo com os dados, os profissionais entendem que há uma inversão da demanda e se reconhecem como demandantes. Por um lado, a demanda pode estar voltada à realização do atendimento ao familiar, segundo a linha de cuidado oferecida pelo serviço com a qual o profissional se identifica e concorda e, por outro lado, pode estar voltada ao cumprimento do que é estabelecido pela instituição, reproduzindo uma prática, naturalizada por ela. Assim, para o atendimento eles precisam dos familiares que, com suas faltas, estão impedindo que a demanda seja respondida, como exemplificado no relato: [...] Realmente, espera aí, calma aí: o que é que vamos fazer com isso? Porque se elas não vêm, como vamos lidar com isso se a gente precisa delas? [...] (Profissional 5).

\section{Oferta e captura}

[...] Alguns fogem, fogem de tal forma que fica até complicado para gente, o trabalho. Porque a família é fundamental no processo, no atendimento [...] algumas demandas que acabam sendo nossas (Profissional 3). Estariam os familiares "fugindo" de algo que os captura? Essa captura, neste caso, se faz pelos atendimentos que esses familiares se negam a comparecer. No entanto, o desvencilharse da captura exercida pela oferta não quer dizer que o familiar encontrou uma alternativa para sua condição. [...] Às vezes eu não quero vir, às vezes falo 'vou e não vou', às vezes me dá vontade de sair andando e não voltar para casa. Não penso em mim, então não venho em reunião aqui. (Familiar 8).

Esses encontros também são vistos por familiares como algo que não muda em nada a sua condição. Assim, não aumentam a potência desses sujeitos, não são bons encontros: [...] Tem coisas que eu vou mesmo pra marcar presença. Eu acho muito pequeno, não sei se eu sou muito exigente, eu prefiro... Porque eu acho tudo... Eu queria que tivesse algo que me preenchesse, aquela coisa grande, sabe, que você fala: 'tem coisa além daquilo que eu penso'. Então tá tudo dentro daquele mundinho que eu já tenho e fica tudo muito monótono [...] (Familiar 3).

Para alguns familiares, ainda, esses encontros representam mais um encargo que devem arcar dentro dos cuidados com seu ente com transtorno mental: [...] Uma vez eu tava muito cansada, eu falei para minhas filhas: a multi é para vocês agora, vocês é que vão participar; mas elas trabalham... Não é todas as vezes que elas podem vir [...] (Familiar 9).

Assim, os sentidos desses encontros com os profissionais, dados por esses familiares, a partir destes relatos, podem ser resumidos em: encontro a ser evitado, não traz acréscimo algum a suas vidas, é mais um encargo no cuidado de seu familiar com transtorno mental. Diante disso, fica evidente a importância de elucidar as reais necessidades dessas pessoas e os possíveis modos de satisfazê-las.

\section{Elucidação das necessidades \\ $X$ “a gente é que entende"}

Para Teixeira ${ }^{18,19}$, as necessidades, que se constituem naquilo de que precisamos para ter saúde, para viver bem, para ser feliz, não são sempre imediatamente transparentes e jamais estão definitivamente definidas e é sempre objeto de um debate interminável. A princípio podemos dizer que se trata de escutar as necessidades dessas pessoas. Alguns profissionais colocam a escuta, o escutar o que têm a dizer os familiares, como fundamental no atendimento à pessoa com sofrimento psíquico: [...] Em alguns casos, pelo menos pra mim, esta escuta é sempre prioritária, no sentido de lapidar ou de constituir melhor esta demanda. (Profissional 8). De que escuta fala esse profissional? Muito se discute sobre a escuta como uma condição básica para o bom atendimento em saúde, como destacam os trabalhos de Durães-Pereira et al. ${ }^{20}$, Ferreira $^{21}$ e Mori e Coelho ${ }^{22}$. No entanto, é importante esclarecer a natureza da escuta, aquilo que se quer escutar. Ainda que seja um elemento fundamental na interação profissional/usuário na prática em saúde, a escuta pode ser tão objetiva (para diagnósticos de diferentes ordens, por exemplo) que são desprezadas, ou consideradas como ruídos de comunicação, conteúdos do discurso do usuário, de importância primordial para compor essa relação de atenção e cuidado ${ }^{23}$. Seria uma escuta dirigida a um fim preestabelecido pelo profissional ao qual o usuário não tem acesso, ficando alienado em relação a esse obje- 
tivo. Seria um diálogo solitário, um que fala sem ressonância e outro que ouve só o que quer ouvir, conforme ilustra o relato a seguir: [...] Poucos falam porque a gente fala muito. A gente quer que o familiar entenda isso e entenda aquilo. Sai sem entender! [...] Então se a gente pudesse ter escuta para uma fala e essa fala pudesse ressoar, a coisa caminharia mais rápido (Profissional12).

$\mathrm{Na}$ busca pelas reais necessidades desses familiares, é importante que haja uma escuta diferenciada, uma abertura para o "autêntico interesse em ouvir o outro”, com propõe Ayres ${ }^{23}$, um legítimo diálogo que promova um acolhimento das dimensões existenciais dessas pessoas. Às vezes, a atribuição do menos, da falta ao familiar justifica, para o profissional, o não interesse por aquilo que é oferecido e tão valorizado: [...] A gente é que entende este discurso do que é atendimento de família, da importância. Às vezes o outro, ainda mais na classe, numa outra cultura, vamos dizer assim, não consegue entender tanto a importância disso como a gente (Profissional 6). A valoração positiva ao atendimento é dada pelo profissional, é ele que sabe que o que oferece é bom para o familiar. Para o familiar resta aceitar apesar de não entender as qualidades da oferta. Espinosa, em sua obra Ética ${ }^{8}$, nos traz que não se trata de negar a competência do sábio, mas de reconhecer que ninguém pode ser competente pelo outro. Trata-se de (re) conhecer que a potência pode aumentar ou diminuir, dependendo da relação com outras singularidades, em razão da qualidade dos encontros, como explicado anteriormente neste estudo. Ao contrário de olhar a falta em relação ao que eu posso, olhar o que cada um pode, afirmar a alteridade, outros modos existenciais, outros modos relacionais.

Na prática em saúde, o usuário, muitas vezes consente, autoriza ao profissional a tomada de competência e a dizer o que é bom para ele, fato exemplificado nos relatos abaixo: [...] Então assim, sabe, tudo o que mandam fazer, não é que vou porque eu sei que tá não, mas se chega um profissional e diz que precisa ir num lugar assim, assim, eu disponibilizo e vou. Aonde eles tão mandando eu levar, eu to levando (Familiar 3). [...] E tem também porque a gente faz mais ou menos uma indicação. Por exemplo, aqueles familiares que a gente acha que têm boa relação, que dão conta, a gente indica normalmente a multi porque a gente acha que o grupo vai dar conta. (Profissional 5). O grifo "a gente", do relato do Profissional 5, refere-se apenas aos profissionais - à equipe multiprofissional - e não aos sujeitos envolvidos na relação referida: profissional e familiar. Voltamos à discussão: se não acontece um encontro entre profissional e usuário, uma conversa em que há genuíno interesse em ouvir e se ouvir, do primeiro acolher às dimensões existenciais do outro, o conhecimento das necessidades não será alcançado, as demandas efetivas não surgirão e as ofertas poderão ser equivocadas. [...] Aí a gente discute um direcionamento, algumas coisas que a gente vem percebendo e isto é dialogado, trabalhado com a família. Por exemplo, a gente discute o BPC [benefício], como esse BPC está sendo aplicado, matrícula na escola, as AVD [atividades da vida diária], no caso dele [...] (Profissional 9). Assim, familiares passivos e dependentes do serviço, com profissionais de saúde mental que, assumindo a resolução de problemas do cotidiano dessas pessoas, parecem desacreditar em suas capacidades de conduzir a própria vida. Mais uma vez aparece o saber do profissional que o autoriza (e é autorizado) a ser competente pelo outro.

Martins $^{24}$ afirma que em toda situação em que nos deparamos com uma verdade pronta, algo que nos é imposto, sentimo-nos invadidos, impotentes e o devir e a vida se tornam pesados e nos oprimem.

\section{O que querem esses familiares?}

$\mathrm{Na}$ entrada da pessoa com sofrimento psíquico no circuito de tratamento, seus familiares ao darem como sentido à loucura, à doença mental, que "não tem cura", passam a não acreditar no seu ente que está em tratamento e nem mesmo nos serviços de saúde mental e seus profissionais. O limite está na associação que correntemente se faz do doente mental com invalidez, com impossibilidade de sair desse lugar ${ }^{25}$. Como forma de lidar com essa alteridade, buscam vigiar e controlar, formas de lidar com a doença mental apoiadas, algumas vezes, pelos profissionais de saúde que orientam os familiares nesse sentido: [...] Eu tenho que vigiar 24 horas. O doutor X falou: 'Dona $H$, a senhora tem que domar a fera porque se ele perceber que a senhora tem medo dele, a senhora está perdida. Ele é o contrário, ele tem que ter medo da senhora. Ele tem medo de mim, ele me respeita, tudo ele me pede [...] (Familiar 9). [...] Aí a psicóloga falou assim: 'de fato tem que ter atenção dobrada com ele. Ele só sai se a gente deixar. Ultimamente a gente está tirando a chave da porta. (Familiar 3).

Vigiar, controlar, dominar, submeter, trancar a loucura, presente nos relatos acima, são práticas que se aproximam à práticas manicomiais. Talvez os motivos para essas práticas possam ser 
explicados de outras formas, diferentes dos motivos que legitimavam as práticas nos manicômios; por exemplo, como medida de proteção da própria pessoa com transtorno mental, que está colocando em risco a própria vida. Proteção de seus membros é uma das funções da família. No entanto, essas práticas parecem estar a serviço de defesa contra a dor e sofrimento que a loucura traz ao abalar o suposto equilíbrio da família e convidá-la a novos modos de existência. De qualquer forma, o louco como doente mental é colocado como incapaz, irresponsável, perigoso, controlado e excluído em espaços fechados. Neste caso, esse espaço é a própria família e a lógica manicomial é sustentada pelos familiares. Estar junto à família, para a pessoa com transtorno mental, nem sempre é garantia de convívio social, de ver afirmado seu modo de ser e estar no mundo.

Sendo incurável o transtorno mental, ficam limitadas as expectativas dos familiares sobre o serviço de saúde mental em relação ao tratamento que tem a oferecer: [...] Não tem, não tem como ajudar uma pessoa assim, não. Ajudar ele é zelar por ele, cuidar, dar banho, dar remédio. O CAPS é mais nesse cuidado. [...] É muito pesado isto aqui. Amanhã, por exemplo, eu fico sozinha em casa, bordando, cuidando das plantas. Aí eu relaxo. Isto pra mim já é uma ajuda (Familiar 3). O CAPS é como um lugar para essas pessoas estarem, poderem ter seus cuidados básicos, aliviando o encargo dos familiares, o cotidiano conturbado com seu ente com sofrimento psíquico, não aparecendo expectativas no sentido de mudanças dessa situação.

$\mathrm{Na}$ visão de alguns desses profissionais, a medicalização para os usuários, seria forte demanda desses familiares e razão de vínculo com o CAPS: [...] Esse imaginário, esta representação que a sociedade tem não é diferente da representação da família e muitas vezes ela vem com a expectativa que a medicação, a consulta psiquiátrica vai resolver o problema. Então muitas vezes vem com uma visão medicalizante e acha que apenas a medicação vai dar conta [...] (Profissional 1). Ao contrário, para esses familiares, o CAPS mostra-se como substitutivo a tratamentos anteriores que se restringiam a intervenção medicamentosa: [...] Encaminhavam, ele ia. Aí passavam um medicamento que ele ficava assim, tontão, o Tegretol. Mas isso foi no começo, no começo. E aí fiquei com medo e parei. [...] Então, encaminharam ele pra cá. A gente não pode esperar melhora assim de uma vez, isso aí eu tô vendo aqui... (Familiar 3).

A medicação também aparece nos discursos, nos diálogos com os psiquiatras dos CAPS, quando é motivo de preocupação por sua associação a mudanças evidentes de comportamento de seus familiares com sofrimento psíquico: [...] Aí eu fui pro médico: Olha, isso aí é medicação, ele não pode ficar desse jeito, sem ânimo. Vamos mudar a medicação, se não ele vai ficar abestalhado e abestalhado não é o que eu quero. Que ele grite, que ele faça, que ele mexa nas coisas, ele tá ativo, não é uma pessoa morta viva. Não quero isso aí, pelo amor de Deus! (Familiar 6). Ao mesmo tempo em que os familiares querem dividir com o CAPS a tarefa de vigiar e controlar seu ente e poder ter um tempo para si, não querem a medicação como forma de contenção dessas pessoas e enxergam no CAPS a possibilidade de outras vias de atenção e cuidado.

No entanto, a contenção pode estar associada a outras demandas, como à ocupação: [...] Um desenho, um bordado porque ela fica muito ociosa. [...] Ela tinha que ir todo dia e ser ocupada todo o dia. (Familiar 4). [...] Meu vizinho falou: 'Dona S., por que a senhora não leva a $H$. pra Pestalozzi, para ela pintar, fazer alguma coisa?' 'Sabe que você tá pensando bem?' A H. precisa disso. (Familiar 7).

Por que essas pessoas precisam ser ocupadas? A ocupação/trabalho como forma de tratamento nasceu com a psiquiatria, sendo importante elemento da lógica asilar. Com a função de organização de tempo, espaço e moral dos internos, o trabalho em manicômios é tão antigo como o próprio manicômio. Mangia e Nicacio ${ }^{26}$ apontam que muitas vezes as atividades não se constituem em oposição à internação, "pelo contrário a evidenciam, conservando a lógica de controle, sujeição e exclusão da própria instituição". Nesta lógica, a atividade mantém as pessoas entretidas, alienadas de sua condição. Para Saraceno" 27: "Entreter para manter dentro pode ser manter dentro da hospitalização, dentro da cultura psiquiátrica, que no lugar de produzir saúde reproduz enfermidade".

Em outra lógica, nas ultimas décadas, com o processo de desinstitucionalização, as atividades são largamente utilizadas em oficinas terapêuticas e na terapia ocupacional, pois são meios importantes de promoção de encontros, além de abrir possibilidades de produção e (re) invenção, de expressão, de experimentação, de variações da vida, de valorização dos processos de subjetivação.

Assim, fazem parte da ocupação dois lados antagônicos: um dos lados serviu ao manicômio, como contenção e controle, e outro lado serviu à desinstitucionalização da loucura, como abertura de possibilidades para a pessoa com transtorno mental. Estes dois tipos de elaboração podem estar presentes, intuitivamente ou não, quando os familiares trazem essa demanda. Portanto, 
por trás da demanda de atividades pode estar a necessidade em intensificar seu tratamento, ampliando sua possibilidade de recuperação/valorização de potencial. No entanto, inversamente, pode estar presente, de forma implícita, o desejo de controle da loucura, numa tentativa de conter o impacto que esta provoca sobre o suposto equilíbrio familiar.

\section{Considerações finais}

Longe da pretensão de esgotar o assunto, acreditamos ser importante o surgimento de outras formas de analisar a demanda, oferta e necessidades de familiares de pessoas com sofrimento psíquico, na relação com o profissional de saúde mental. Ressaltamos a importância de um olhar para a não relação, ou seja, a recusa do encontro, quando são necessárias intermediações institucionais ou mesmo da justiça para que a família se responsabilize pelo tratamento do seu ente com transtorno mental e concorde em participar dos atendimentos. Porém, um aprofundamento na questão é indicação para outro estudo de relevância para a área. Assumimos uma análise que vai além da dicotomia oferta-demanda e procuramos considerar o trabalho em saúde no cotidiano do agir profissional, suas relações e seu contexto. Desta forma não partimos de um fluxo modelo de oferta-demanda, mas valorizamos as imanências do campo de relações entre profissional e familiar, na proposta de atenção e cuidado em saúde mental, na organização do serviço.

A disparidade entre oferta dos profissionais e demanda dos familiares mostra a ausência de diálogo em que, assumindo-se como único competente, o profissional resolve o que é bom para o familiar, sem escutá-lo, sem (re) conhecer a sua potência, sem buscar suas reais necessidades.

Esse questionamento, ou mesmo recusa do tratamento oferecido, pode indicar tomada de posição dos familiares, saindo de uma postura, muitas vezes esperada, de passividade na relação com o profissional e com o serviço. Isso pode ser entendido como manifestação de potência desses familiares, demonstração do que são capazes diante de uma situação em que questionam o que muitas vezes lhes é colocado como inquestionável, pela hierarquia da relação e polarização do saber no profissional.

Alguns autores, como Bauleo ${ }^{28}$ e Baremblitt $^{29}$, afirmam que as pessoas, a comunidade, a população demandam um atendimento no qual já está interiorizada a oferta que a instituição ministrou a essa mesma população. Na mesma linha, autores $^{15,30}$ afirmam que a demanda é socialmente construída, está relacionada ao perfil do serviço de saúde e à forma como se processa a produção de cuidado e as relações entre profissionais de saúde e sua clientela. Dessa forma, o desejo de controle do seu familiar com sofrimento psíquico só se traduz nas demandas citadas porque encontra na instituição um campo propício para esta formulação, isto é, endereçam ao CAPS demandas manicomiais, pois identificam nas ações e ofertas da instituição possibilidades de satisfazê-las.

Diante do exposto, é importante refletirmos quais os impactos dessa forma que vem sendo trabalhada a relação profissionais-familiares, demanda-oferta na prática de atenção à saúde mental, sobre a consolidação do processo de desinstitucionalização e das políticas de saúde mental. A disparidade entre oferta dos profissionais e demanda dos familiares, a ausência de negociação de necessidade, conforme exposto neste estudo, mostra que o trabalho no território, o resgate de saberes, recursos da comunidade devem ser mais bem valorizados para construção conjunta de soluções. Da mesma forma, é importante que a oferta vá ao encontro do sofrimento subjetivo associado ao transtorno mental, ao sofrimento associado, ao cotidiano e à sobrecarga dos familiares no dia a dia partilhado com a pessoa em sofrimento psíquico. O projeto terapêutico singular (PTS) seria a resposta para estas questões, pois tem como elemento central de articulação a singularidade, considerando projetos e desejos do indivíduo, sua relação com a doença, sua história de vida ${ }^{31}$. No entanto, só será viável se houver um bom encontro entre profissional-usuário e profissional-familiares, para que esse possa ser formulado e negociado.

O bom encontro, como discutido neste estudo, gera alegria e aumento de potência dos sujeitos envolvidos, terreno fértil para autonomia e protagonismo de usuários, familiares e profissionais, condição necessária para a consolidação da reforma psiquiátrica, que somente é exequível a partir da participação ativa destes sujeitos.

Em relação aos profissionais de saúde mental - apesar de espaços como formação permanente, reuniões de equipes, supervisões, apoio matricial -, nota-se que muitos deles estão apenas colocando em prática as políticas e modelos propostos, sem a reflexão e avaliação constante do impacto que esse tipo de trabalho exerce sobre sua subjetividade. Como resultado, os profissionais de saúde podem ter como palavra de ordem a cida- 
dania e ter ações que desconsideram a potência da pessoa em sofrimento psíquico e de seus familiares; têm ações de tutela destas pessoas, não diferenciando das práticas manicomiais. Refletir sobre o lugar da prática do profissional em saúde mental requer o reconhecimento de que esta se situa em uma região de fronteira em relação ao controle social. O cuidado e seu desenvolvimento na área estão ligados ao exercício de uma contradição. Operar a favor da contratualidade em casa, no trabalho e na rede social é colocar em prática a inversão da lógica da tutela, é compartilhar com a pessoa com transtorno mental, sua família e a comunidade um trajeto que possibilite a (re) construção de autonomia e cidadania.

\section{Colaboradores}

TC Constantinidis e AN Andrade trabalharam igualmente em todas as etapas de elaboração do artigo. 


\section{Referências}

1. Brasil. Ministério da Saúde (MS). Reforma Psiquiátrica e política de Saúde Mental no Brasil- Conferência Regional de Reforma dos Serviços de Saúde Mental: 15 anos depois de Caracas. Brasília: MS; 2005.

2. Brasil. Ministério da Saúde (MS). Legislação em saúde mental: 1990-2004. Brasília: MS; 2004.

3. Colvero LA, Ide CA, Rolim MA. Família e doença mental: a difícil convivência com a diferença. Rev Escola de Enfermagem da USP 2004; 38(2):197-204.

4. Rosa LCS. A inclusão da família nos projetos terapêuticos em saúde mental. Psicologia em Revista 2005; 11(18):205-218.

5. Villares CC, Mari JJ. Esquizofrenia e contexto familiar. In: Shirakawa I, Chaves AC, Mari JJ, organizadores. O desafio da esquizofrenia. São Paulo: Lemos Editorial; 2005.

6. Rosa LCS. Transtorno mental e o cuidado na família. São Paulo: Cortez; 2003.

7. Gonçalves AM, Sena RR. A reforma psiquiátrica no Brasil: contextualização e reflexos sobre o cuidado com o doente mental na família. Rev Lat-Am enferm 2001 9(2):48-55.

8. Spinoza B. Ética/Spinoza. Trad. e notas de Tomaz Tadeu. Belo Horizonte: Autentica Editora; 2007.

9. Spinoza B. Tratado Político, Benedictus de Spinoza. São Paulo: Ícone; 1994

10. Pinheiro R. As práticas do cotidiano na relação oferta e demanda dos serviços de saúde: um campo de estudo e construção da integralidade. In: Pinheiro R, Mattos RA, organizadores. Os sentidos da integralidade na atenção e no cuidado à saúde. Rio de Janeiro: IMS/UERJ, Abrasco; 2001. p. 65-112.

11. Minayo MCS. O desafio do conhecimento: pesquisa qualitativa em saúde. São Paulo: Hucitec; 2007.

12. Serapioni M. Métodos qualitativos e quantitativos na pesquisa social em saúde: algumas estratégias para a integração. Cien Saude Colet 2000; 5(1):187-192.

13. Brasil. Ministério da Saúde (MS). Conselho Nacional de Saúde. Resolução no 196 de 10 de outubro de 1996. Diretrizes e Normas Regulamentadoras de Pesquisas Envolvendo Seres Humanos. Diário Oficial da União 1996; 16 out.

14. Turato ER. Tratado da metodologia da pesquisa clínicoqualitativa. Petrópolis: Vozes; 2008.

15. Bardin L. Análise de Conteúdo. Lisboa: Edições 70; 1979.

16. Franco TB. As Redes na Micropolítica do Processo de Trabalho em Saúde. In: Pinheiro R, Mattos RA, organizadores. Gestão em Redes: práticas de avaliação, formação e participação na saúde. Rio de Janeiro: CEPESC, IMS/UERJ, Abrasco; 2006.

17. Franco TB, Merhy EE. Produção Imaginária da Demanda. In: Pinheiro R, Mattos RA, organizadores. Construção Social da Demanda. Rio de Janeiro: IMS/ UERJ, CEPESC, Abrasco [internet] 2005. [acessado em 2010 agosto 12]. Disponível em: http://www.uff. br/pgs2/textos/producao-imaginaria-da-demanda.pdf

18. Teixeira RR. Acolhimento num serviço de saúde entendido como uma rede de conversações. In: Pinheiro R, Matos RA, organizadores. Construção de integralidade - cotidiano, saberes e práticas em saúde. Rio de Janeiro: IMS/UERJ, Abrasco; 2003. p. 49-61.
19. Teixeira RR. Agenciamentos tecnosemiológicos e produção de subjetividade: contribuição para o debate sobre a trans-formação do sujeito na saúde. Cien Saude Colet 2001: 6(1):49-61.

20. Durães-Pereira MB, Novo NF, Armond JE. A escuta e o diálogo na assistência ao pré-natal na periferia da zona sul do município de São Paulo. Cien Saude Colet 2007; 12(2):465-476

21. Ferreira JO. Programa de humanização da saúde: dilemas entre o relacional e o técnico. Saúde soc 2005; 14(3):111-118.

22. Mori ME, Coelho VLD. A vida ouvida: a escuta psicológica e a saúde da mulher de meia idade. Estudos e pesquisas em psicologia 2003; 3(2):1-12.

23. Ayres JRCM. O cuidado, os modos de ser (do) humano e as práticas de saúde. Saúde soc 2004; 13(3):16-29.

24. Martins A. Biopolítica: o poder médico e a autonomia do paciente em uma nova concepção de saúde. Interface (Botucatu) 2004; 8(14):21-32.

25. Scarcelli IR. O movimento da luta antimanicomial e a rede substitutiva em saúde mental: a experiência do município de São Paulo [manuscrito]. São Paulo: Instituto de Psicologia USP; 2008.

26. Mângia EF, Nicácio F. Terapia Ocupacional em Saúde Mental: tendências principais e desafios contemporâneos. In: De Carlo MMRP, Bartalotti C, organizadores. Terapia Ocupacional no Brasil: fundamentos e perspectivas. São Paulo: Plexus; 2001.

27. Saraceno B. Libertando identidades: da reabilitação psicossocial à cidadania possível. Belo Horizonte: Instituto Franco Basaglia/TeCorá; 1999.

28. Bauleo A. Notas de psicologia e psiquiatria social. São Paulo: Editora Escuta; 1988.

29. Baremblitt GF. Compêndio de Análise Institucional e ou tras correntes: teoria e prática. Belo Horizonte: Instituto Felix Guattari; 2004

30. Merhy EE. O ato de governar as tensões constitutivas do agir em saúde como desafio permanente de algumas estratégias gerenciais. Cien Saude Colet 1999; 5(4):305 314

31. Brasil. Ministério da Saúde (MS). Secretaria de Atenção à Saúde. Núcleo Técnico da Política Nacional de Humanização. Clínica ampliada, equipe de referência projeto terapêutico singular. 2a ed. Brasília: MS; 2008.

Artigo apresentado em 03/08/2013

Aprovado em 30/09/2013

Versão final apresentada em 03/10/2013 